\title{
Slot Coupled Ultra Wideband and Multiband Monopole Antennas for Wireless Applications
}

\author{
Mahesh A. Mainderkar \\ P. G. Department \\ MBES College of Engineering \\ Ambajogai, India
}

\author{
Veeresh G. Kasabegoudar \\ P. G. Department \\ MBES College of Engineering \\ Ambajogai, India
}

\begin{abstract}
This article presents a CPW fed capacitive coupled circular shaped monopole antenna. Ground dimensions of the geometry are used to tune the proposed antenna's input impedance (impedance bandwidth). Furthermore, these ground dimensions can be used to make antenna operating either in ultra wideband or multiband mode. Besides these dimensions, the capacitive gap introduced on the circular stub will also decide the working of antenna as either wideband or multiband operation. Capacitive gap may be placed at any point on the circular stub. In this work we investigated its effect at three different places i.e., lower end, at the center, and at the upper end of the geometry. More than $100 \%$ (2$12 \mathrm{GHz}$ band) impedance bandwidth was achieved for UWB antenna design. For multiband antenna design presented, triple bands with impedance bandwidth of 76.58, 35.73, and $23.11 \%$ respectively were obtained. Similar results were obtained for all the cases studied. Measured characteristics fairly agree with the simulated results.
\end{abstract}

\section{General Terms}

Planar CPW Fed Omni-Directional Antennas

\section{Keywords}

Microstrip Antennas, Capacitive Coupling, and Wideband Antennas.

\section{INTRODUCTION}

In recent years, research in the area of ultra wideband system (UWB) has generated a lot of potential in wireless applications [1]. It may be recalled that new definition of FCC on UWB bandwidth $(3.1 \mathrm{GHz}-10.6 \mathrm{GHz})$ has led to rapid growth in wireless applications in this range of frequencies [2]. To meet these demands CPW fed monopole antennas are the right candidates and are most popular in integrated circuits applications because of their ease of integrability into system on chip (SOC) applications. There are several UWB antennas reported in literature [1-15]. For example [1] explains the bandwidth enhancement technique using modified ground plane with diagonal edges. However, the antenna uses finite ground on the back side and hence bandwidth is limited to $18.3 \%$. In another work [3], asymmetric ground plane is used to obtain multiband operations which cover various commercial wireless applications.

On the other hand antenna reported in [4] is a CPW fed slot antenna yields the impedance bandwidth of $52 \%$ and bidirectional radiation patterns. In another effort, antenna presented in [5] is suitable for dual band applications whereas antenna reported in [8] uses meta-materials for the antenna design which yields multiband characteristics. In yet another effort, A. K. Panda et. al., [9] have demonstrated the multiband operation using fractal geometry. In most of the cases reported in literature, either they yield less bandwidth or difficult to fabricate and assemble them.

In this paper, we propose a CPW fed capacitive gap coupled wideband antenna which is suitable for ultra wideband and multiband applications. The capacitive gap is used to tune the antenna operation as either for UWB or for multi band operation. Section 2 presents the basic geometry and its working. Simulation results and antenna geometry with capacitive gap have been presented in Section 3. The experimental investigations and validations of this study are presented in Section 4 followed by conclusions in Section 5 .

\section{BASIC GEOMETRY}

Fig 1 shows the basic geometry of the antenna. The geometry is basically a CPW fed monopole antenna [14]. The substrate used for design and analysis is a glass epoxy material whose properties are chosen as listed in Table 1. Effective dielectric constant can be calculated from the design expressions listed in $[6,7]$. The antenna was optimized using the Ansoft HFSS [16] which is the commercially available electromagnetic software. The physical dimensions of the antenna are listed in Table 1. Detailed parametric studies on this geometry can be found in [14].

The simulated return loss characteristics are shown in Fig 2 . From the Fig 2 it can be noted that the basic geometry operates in the $2-12 \mathrm{GHz}$ band which corresponds to more than $100 \%$ impedance bandwidth $(-10 \mathrm{~dB})$. The radiation patterns at various frequencies in the band of operation are presented in Fig 3. From these patterns, it may also be noted that the patterns start degrading at upper side of the operating frequency band.

In order to obtain ultra wideband operation, ground dimensions of the antenna have been varied and optimized for the ultra wideband operation. It may also be noted that these dimensions ( $L$ and $W$ ) can be varied and optimized for multiband operation. The capacitive gap introduced (pl. ref. Fig 4) will also help in tuning the ultra wideband operation into multiband operation and is explained in next section (Section 3). 


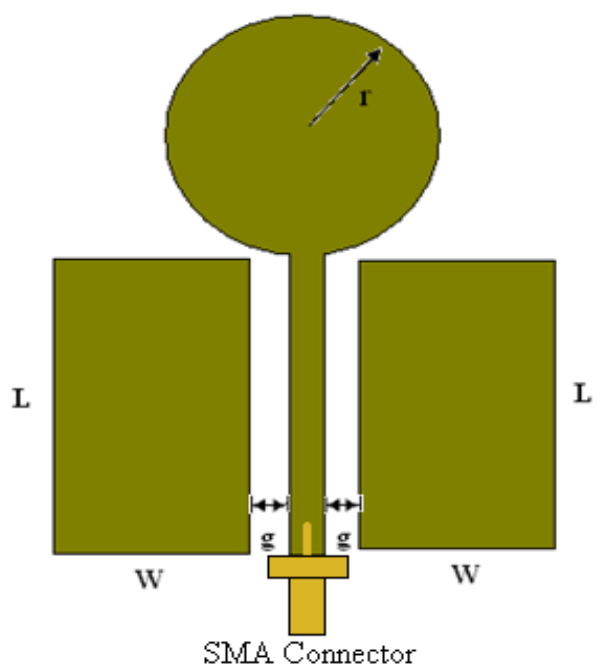

Fig 1: Basic geometry of CPW fed monopole antenna.

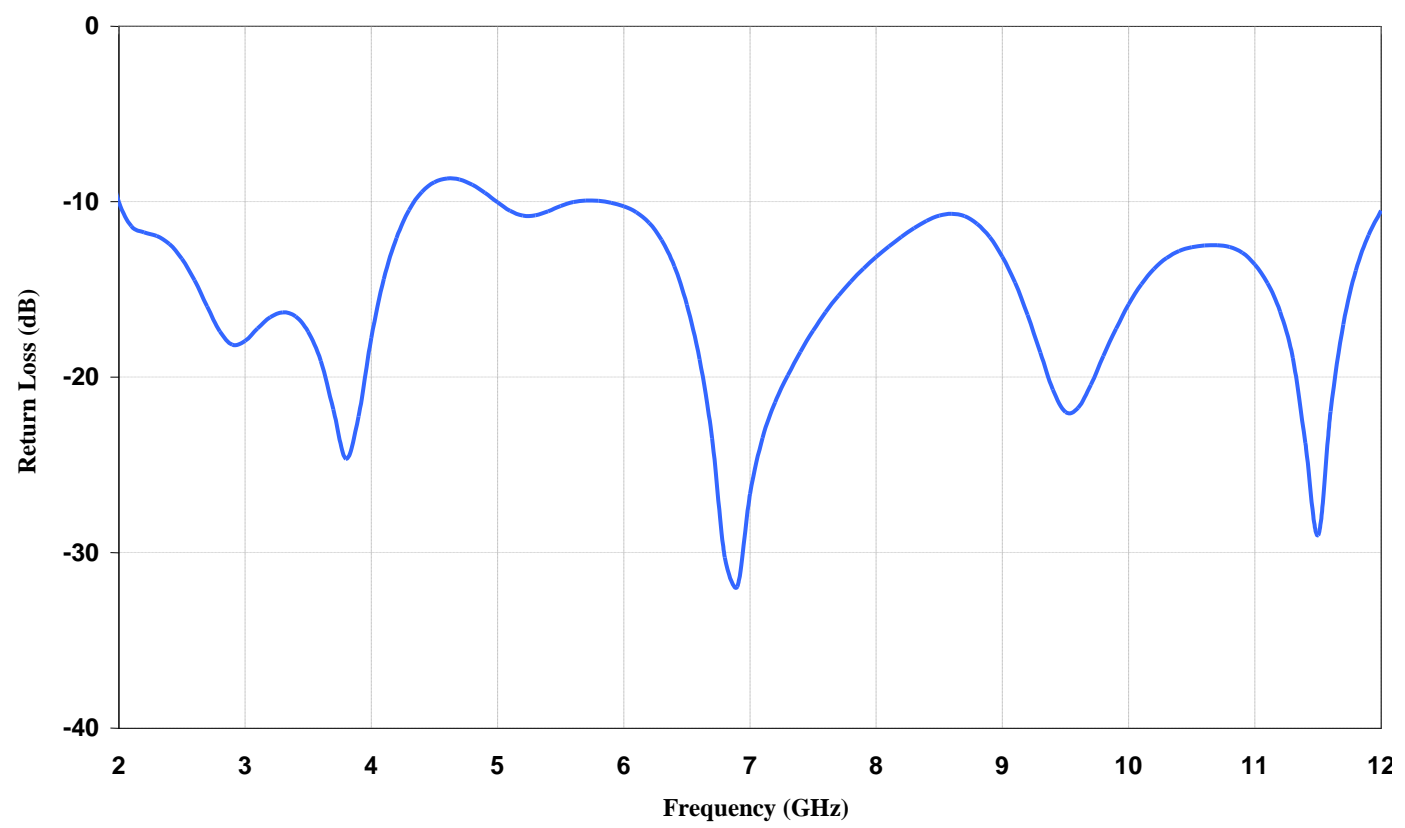

Fig 2: Simulated return loss characteristics of geometry shown in Fig 1.

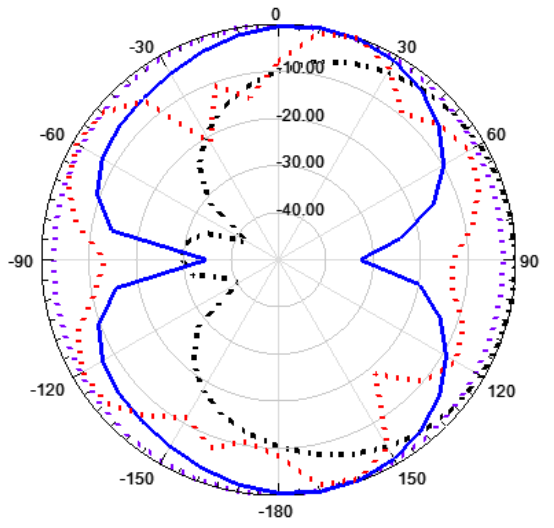

(a) $\mathrm{E}$ and $\mathrm{H}$ plane patterns at $2.4 \mathrm{GHz}$

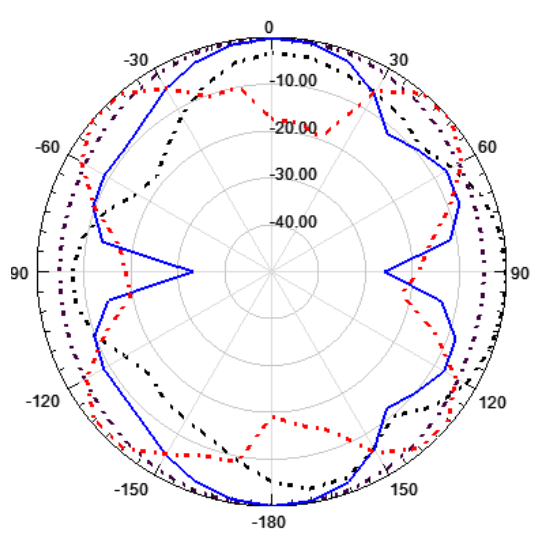

(b) E and $\mathrm{H}$ plane patterns at $3.5 \mathrm{GHz}$ 


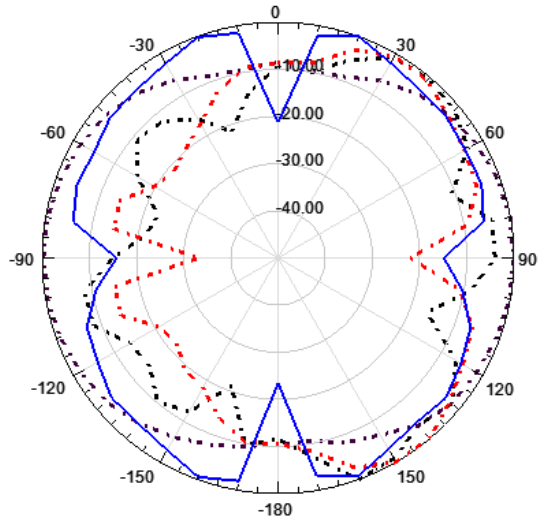

(c) $\mathrm{E}$ and $\mathrm{H}$ plane patterns at $6.5 \mathrm{GHz}$

Fig 3: Radiation patterns of antenna showed in Fig 1 at various frequencies in the band of operation.

Table 1. Optimized dimensions of the proposed antenna

\begin{tabular}{|c|c|}
\hline Parameter & Value \\
\hline Length of ground $(\mathrm{L})$ & $17.0 \mathrm{~mm}$ \\
\hline Width of ground $(\mathrm{W})$ & $15.5 \mathrm{~mm}$ \\
\hline Radius of circle $(\mathrm{r})$ & $16.2 \mathrm{~mm}$ \\
\hline CPW gap $(\mathrm{g})$ & $0.5 \mathrm{~mm}$ \\
\hline Slot gap width $(\mathrm{d})$ & $0.1 \mathrm{~mm}$ \\
\hline Dielectric constant $\left(\varepsilon_{\mathrm{r}}\right)$ & 4.4 \\
\hline Loss tangent $(\tan \delta)$ & 0.001 \\
\hline Height of substrate $(\mathrm{h})$ & $1.6 \mathrm{~mm}$ \\
\hline
\end{tabular}

\section{PARAMETRIC STUDIES AND}

\section{DISCUSSIONS}

As stated in Section 2, the geometry shown in Fig 1 was simulated using Ansoft HFSS software [16]. All key design parameters (ground width $(W)$, ground length $(L)$, and capacitive slot $(d)$ ) have been investigated to analyze the effect on antenna performance and are discussed in the following subsections.

\subsection{Effect of Ground Dimensions on Antenna Geometry}

In order to merge all individual bands and to get the wideband operation suitable for FCC defined applications, ground dimensions have been varied. In the first step ground length was varied in steps of $2 \mathrm{~mm}$ as shown in Fig 5. From Fig 5 it may be observed that $L=23.8 \mathrm{~mm}$ proves to be the optimum. In the next step width of the ground plane was varied from $25.4 \mathrm{~mm}$ to $33.4 \mathrm{~mm}$ keeping optimum value of $L=31.8$ obtained in the first step. Return loss characteristics for this case are presented in Fig 6. From these two steps optimum values of ground dimensions are $L=31.8 \mathrm{~mm}$ and $W=25.4 \mathrm{~mm}$. An effort was also made to vary the circular stub radius from the current value of $16 \mathrm{~mm}$. However, no significant results were obtained for the cases studied (14mm to $18 \mathrm{~mm}$ in steps of $1 \mathrm{~mm})$.

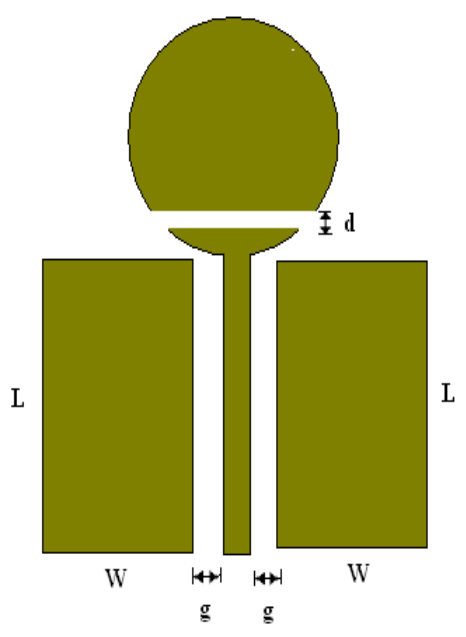

(a)

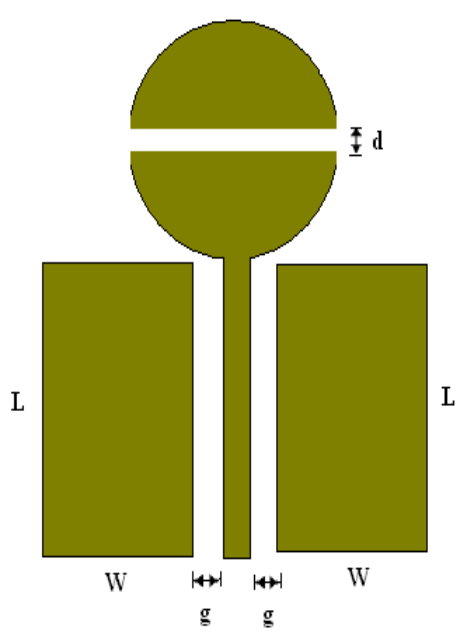

(b)

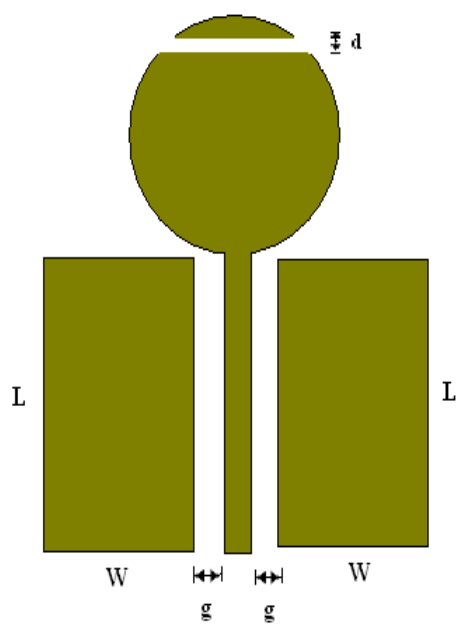

(c)

Fig 4: Gap coupled wideband antenna geometries. A capacitive slot is placed on (a) lower side (b) middle (c) upper side. All other dimensions are as listed in Table 1. 


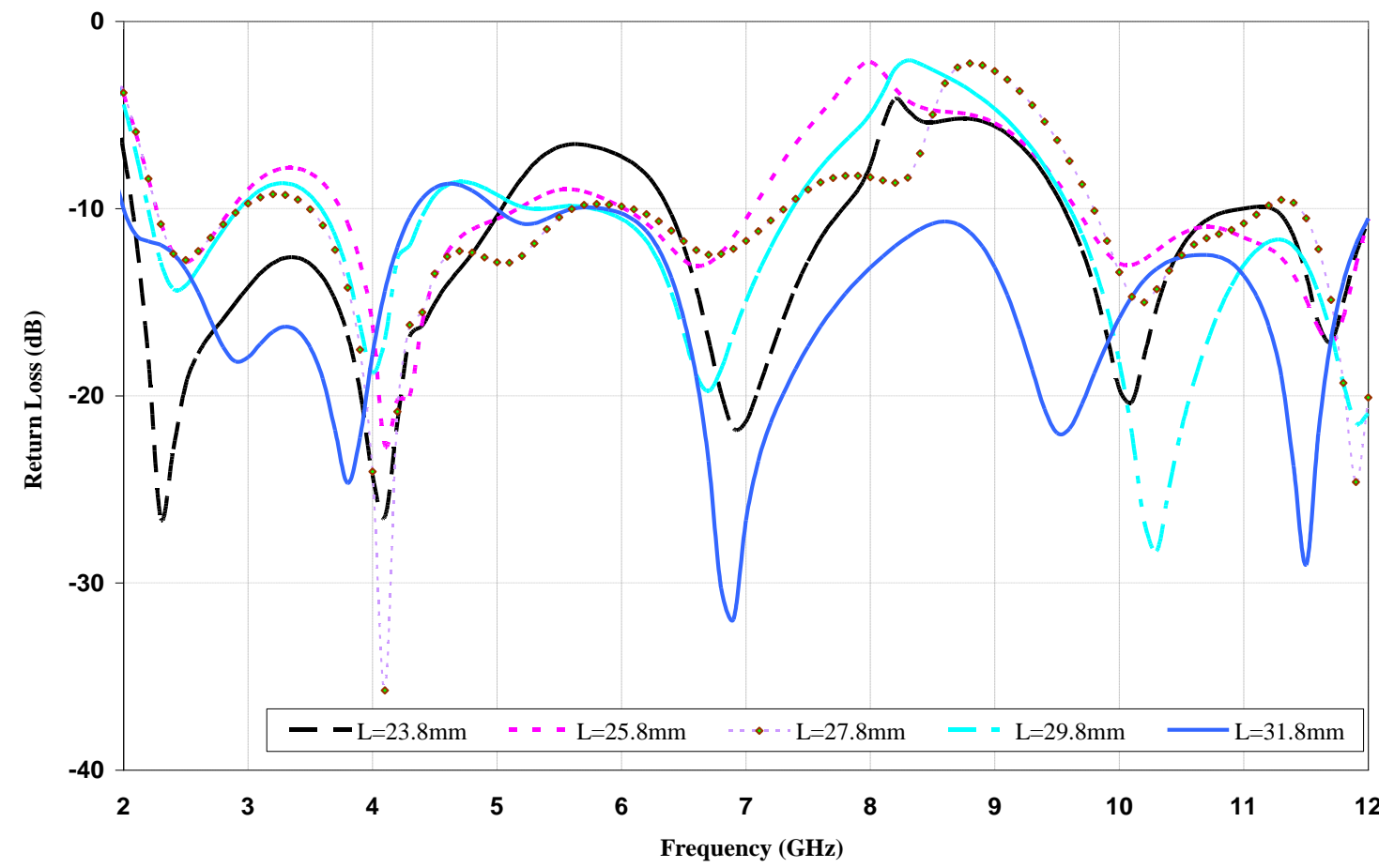

Fig 5: Return loss characteristics for different values of $L$ keeping $W=25.4 \mathrm{~mm}$ constant (All other dimensions are as listed in Table 1).

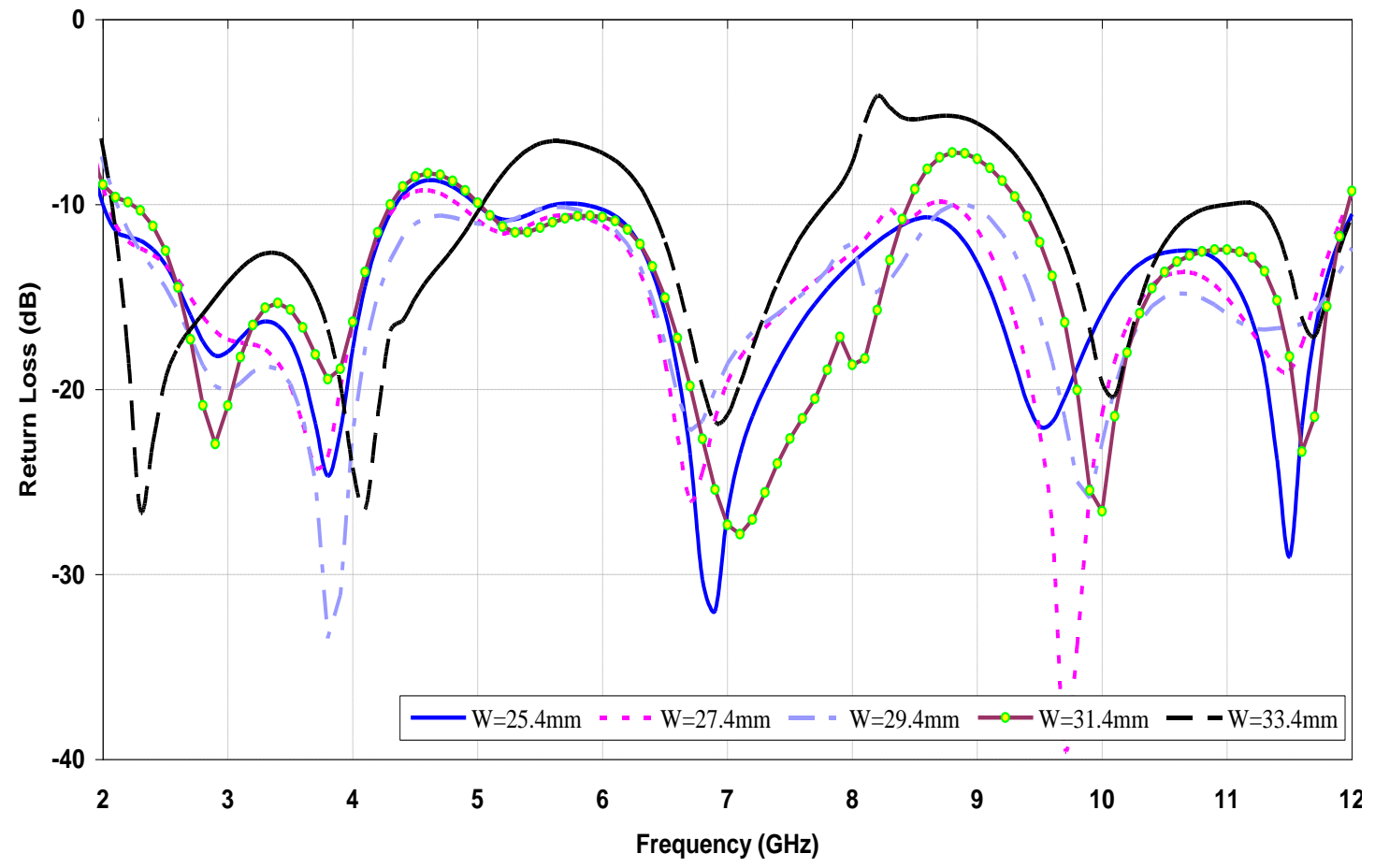

Fig 6: Return loss characteristics for different values of $W$ keeping $L=31.8 \mathrm{~mm}$ constant (All other dimensions are as listed in Table 1). 


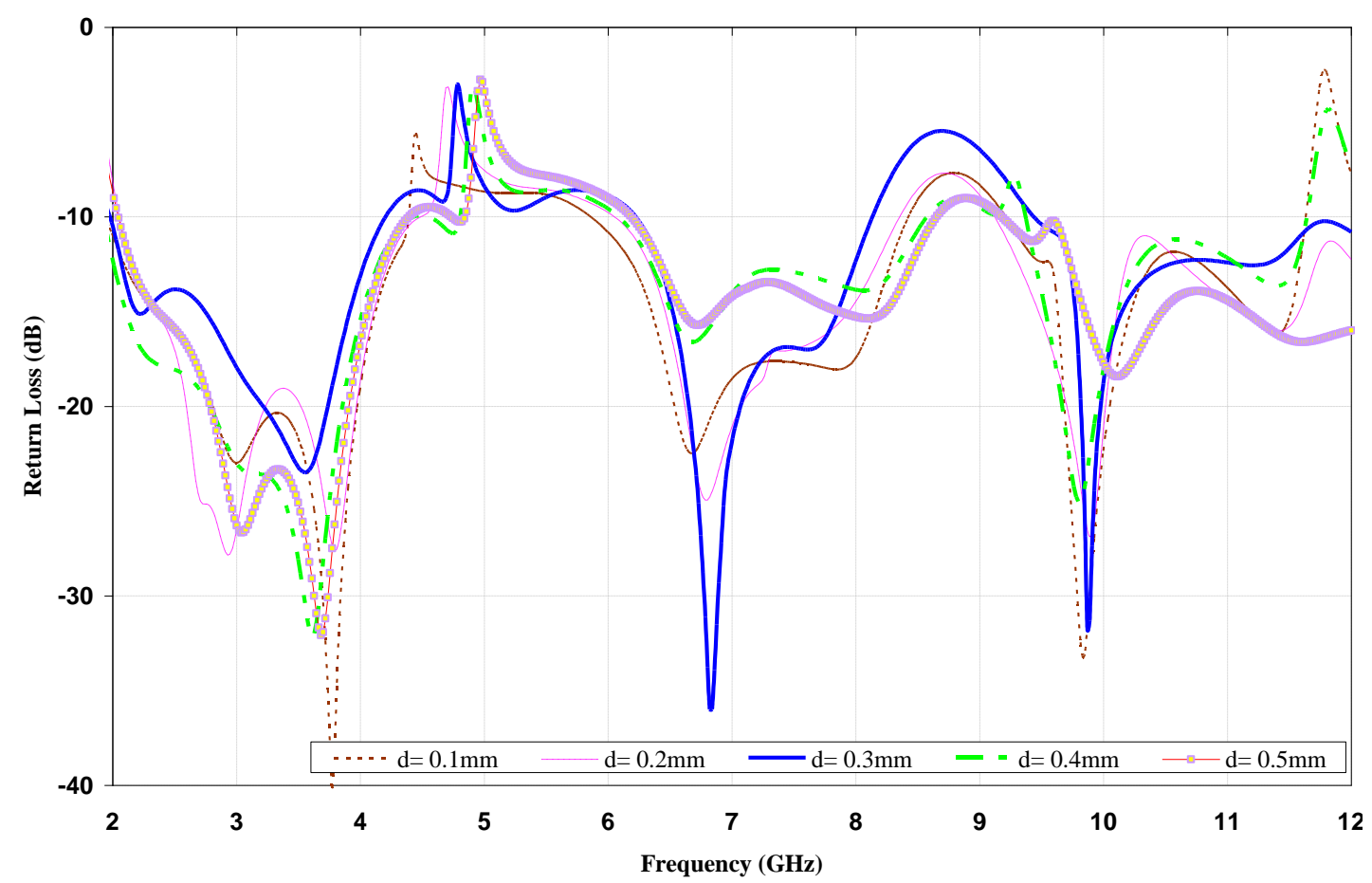

Fig 7: Return loss characteristics for different values of capacitive gap (All other dimensions are as listed in Table 1).

\subsection{Effect of Capacitive Gap}

The geometries of basic antenna with capacitive slot are presented in Fig 4. Slots were introduced at three different positions. These locations are center position, $5 \mathrm{~mm}$ above from center (upper slot), and $5 \mathrm{~mm}$ below from center (lower slot) of the circular geometry. All the cases were investigated with one slot at a time. The slot width $(d)$ was varied in steps of $0.1 \mathrm{~mm}$ by keeping all other dimensions constant. All the results are presented in Table 2. Return loss characteristic for the optimum case is depicted in Fig 7. From the Table 2 it may be noted that $d=0.1 \mathrm{~mm}$ case proves to be the best one as it offers three frequency bands with optimum bandwidth values. Gap width was not reduced below $0.1 \mathrm{~mm}$ because it may be difficult to realize the geometry while fabrication. Similar results were obtained for other two cases (Fig 4(b) \& Fig 4(c)). However, it was observed that for the gap placed at the lower side, the gain was not uniform throughout the bands of operation.

\section{EXPERIMENTAL RESULTS AND DISCUSSIONS}

The geometry shown in Fig 1 was fabricated and tested. The substrate used for the fabrication is FR4 substrate with parameters indicated Table 1. A photograph of the fabricated prototype is shown in Fig 8(a). Return loss comparisons of measured and simulated values are compared in Fig 9(a).
Among the three slot sections presented in Section 3, capacitive slot in the middle (Fig 4 (b)) was fabricated and tested. A prototype of this geometry is shown in Fig 8(b). Return loss characteristics of this geometry are depicted in Fig 9(b). In both cases, measured results fairly agree with their simulated values.

\section{CONCLUSIONS}

A circular shaped CPW fed capacitive coupled monopole antenna has been presented. Ground dimensions of the CPW feed have been varied to obtain UWB operation. The capacitive gap was introduced on the circular stub to obtain multiband operation. Placement of capacitive gap may be at any point on the circular stub i.e., lower end, at the center, and at the upper end of the geometry. Similar results were obtained for all the cases studied. The simulation studies indicate the wideband and multi band operations with good radiation characteristics. For wideband operation more than $100 \%(2-12 \mathrm{GHz})$ impedance bandwidth with good gain throughout the band of operation was obtained. Triple bands were obtained with impedance bandwidth of $76.58,35.73$, and $23.11 \%$ when a capacitive gap was introduced at the middle, and optimized. The basic geometry and geometry with capacitive slot in the middle were fabricated and tested for their validations. In both cases measured results agree with the simulated characteristics. The antenna presented here proves to be the best candidate for FCC defined UWB operation. 
Table 2. Effects of variation of width of capacitive slot $(d)$ on the VSWR bandwidth of the antenna

\begin{tabular}{|c|c|c|c|c|c|c|}
\hline \multirow{2}{*}{ Slot Width (mm) } & \multicolumn{3}{|c|}{ Frequency Range (GHz) } & \multicolumn{3}{c|}{ Bandwidth (\%) } \\
\cline { 2 - 7 } & $\mathbf{1}^{\text {st }}$ & $\mathbf{2}^{\text {nd }}$ & $\mathbf{3}^{\text {rd }}$ & $\mathbf{1}^{\text {st }}$ & $\mathbf{2}^{\text {nd }}$ & $\mathbf{3}^{\text {rd }}$ \\
\hline 0.1 & $1.95-4.37$ & $5.86-8.41$ & $9.22-11.63$ & 76.58 & 35.73 & 23.11 \\
\hline 0.2 & $2.06-4.47$ & $6.06-8.34$ & $9.13-12.0$ & 73.81 & 31.66 & 27.16 \\
\hline 0.3 & $2.00-4.19$ & $6.23-8.12$ & $9.44-12.0$ & 70.76 & 26.34 & 23.88 \\
\hline 0.4 & $1.93-4.41$ & $6.08-8.56$ & $9.37-11.63$ & 78.23 & 33.87 & 21.52 \\
\hline 0.5 & $2.04-4.37$ & $6.19-8.63$ & $9.19-11.95$ & 72.69 & 32.92 & 26.11 \\
\hline
\end{tabular}

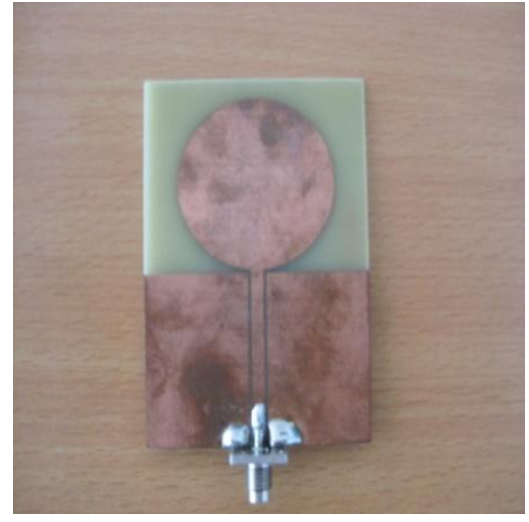

(a)

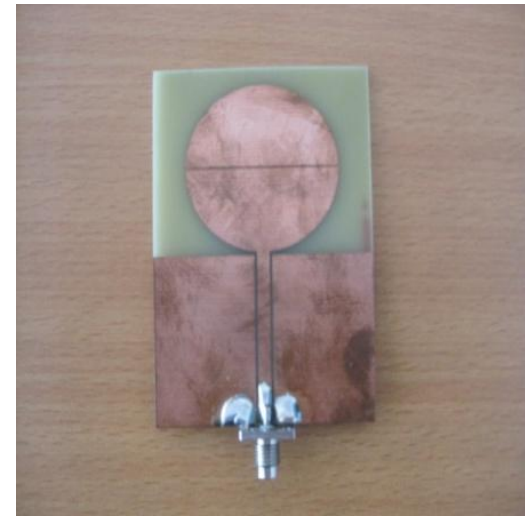

(b)

Fig 8: Prototype of fabricated antenna geometries (a) Basic geometry (b) Geometry with capacitive slot in the middle.

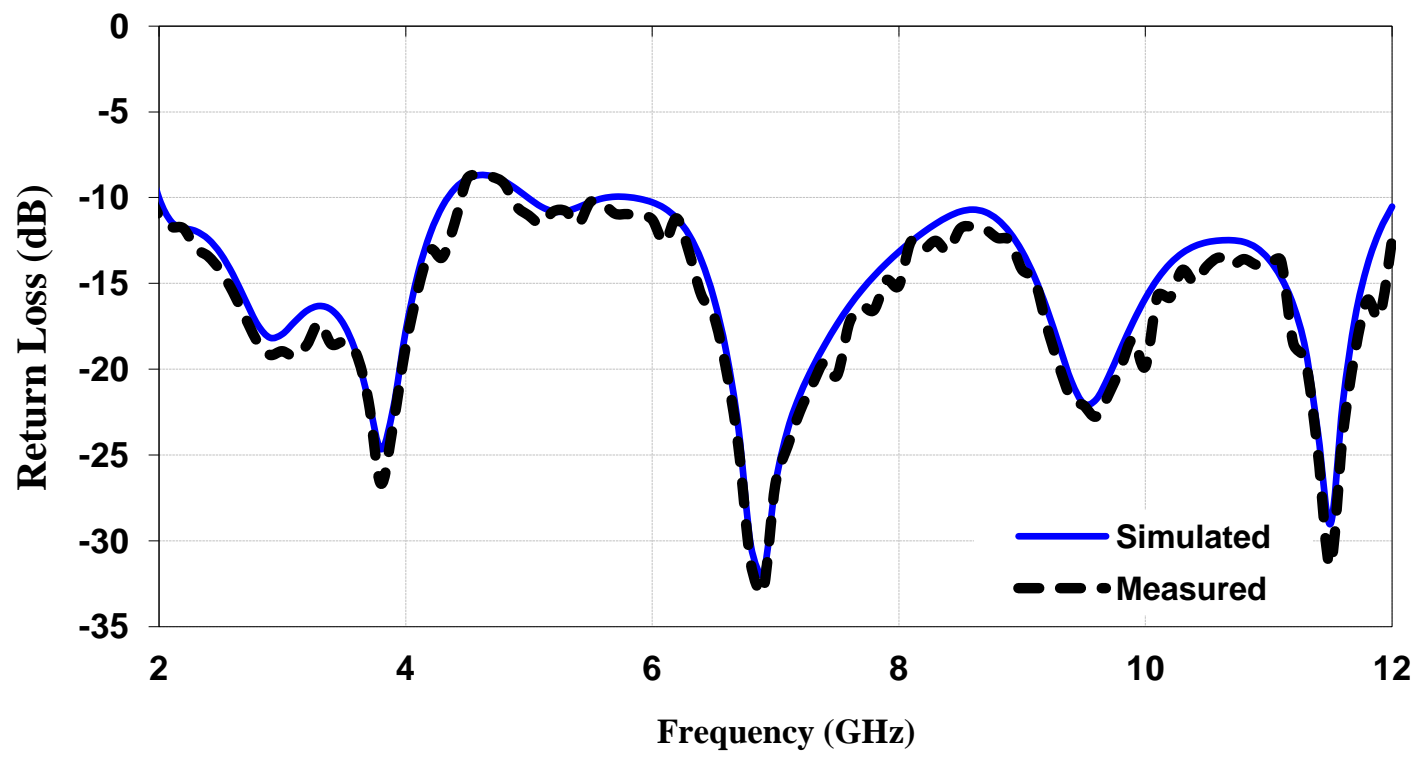

(a) 


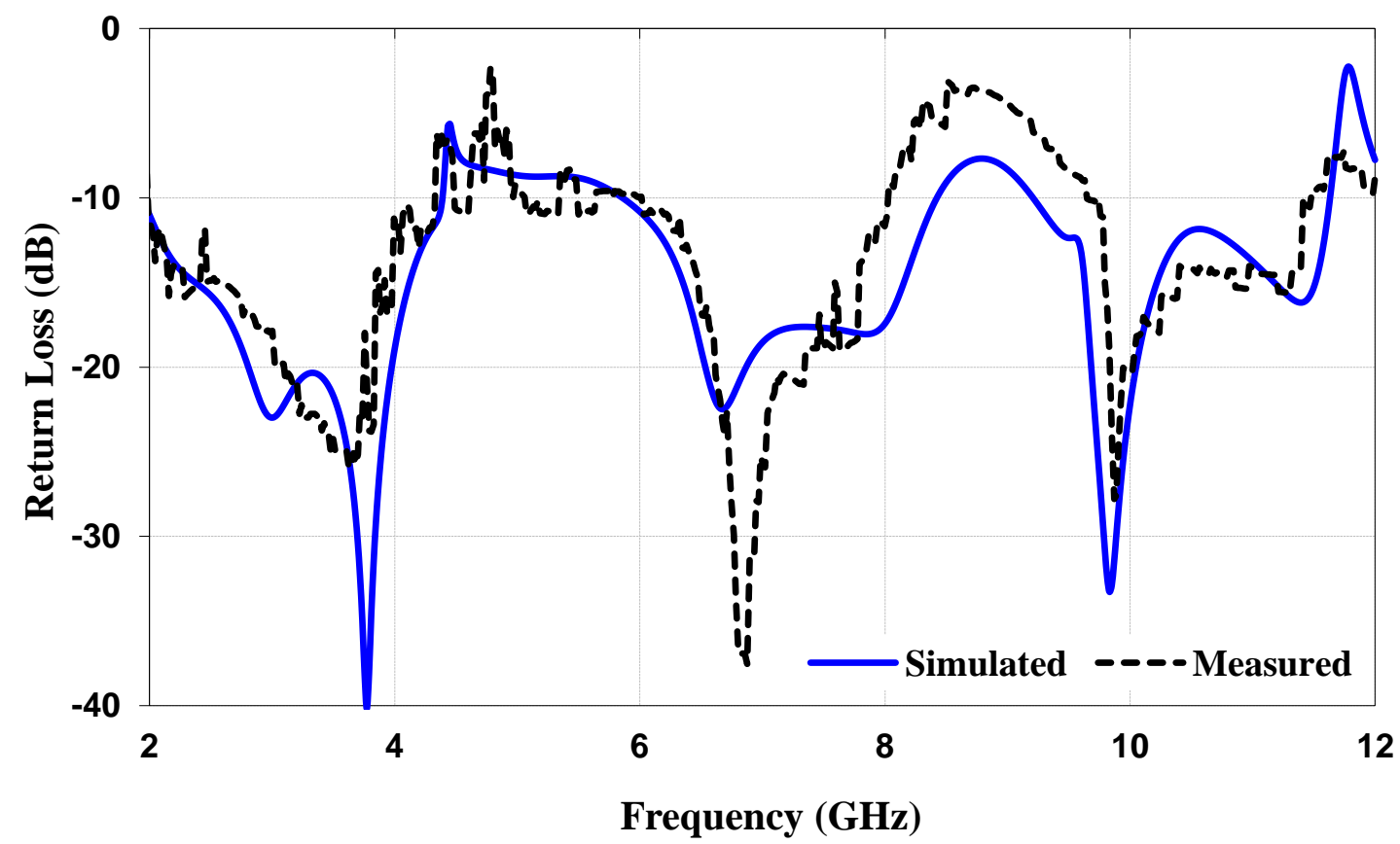

(b)

Fig 9: Return loss characteristics comparisons of (a) Basic geometry (b) Geometry with capacitive slot in the middle of circular monopole.

\section{REFERENCES}

[1]. N. Prombutr, P. Kirawanich, and P. Akkaraekthalin, "Bandwidth increasing technique using modified ground plane with diagonal edges," IETE J. of Research, vol. 55, no. 5, pp. 196-200, 2009.

[2]. V. G. Kasabegoudar, D. Upadhyay, and K. J. Vinoy, "Design studies of ultra wideband microstrip antennas with a small capacitive feed," Int. J. Antennas and Propagat., pp. 1-8, vol. 2007, 2007.

[3]. V. Deepu, R. K. Raj, M. Joseph, M. N. Suma, and P. Mohanan, "Compact asymmetric coplanar strip fed monopole antenna for multiband applications," IEEE Trans. Antennas Propagat., vol. 55, no. 8, pp. 23512357, 2007.

[4]. T. Shanmuganatham, K. Balamaniknandan, and S. Raghavan, "CPW fed slot antenna for wideband applications," Int. J. Antennas and Propgat., pp. 1-4, vol. 2008.

[5]. D. Prakash, R. Khanna, V. Kumar, and A. Chaudhary, "Novel dual-band CPW-fed monopole slot antenna for WLAN/WiMax applications," Int. J. Comp. Sci. \& Tech. (IJCST), vol. 1, no. 1, pp. 21-24, 2010.

[6]. R. Garg, P. Bhartia, I. Bahl, and A. Ittipiboon, Microstrip Antenna Design Handbook, Artech House, Norwood, Mass, USA, 2001

[7]. G. Kumar and K. P. Ray, Broadband Microstrip Antennas, Artech House, Norwood, Mass, USA, 2003.

[8]. L. M. Si, and X. Lv, "CPW fed multiband omnidirectional planar microstrip antenna using composite meta-material resonators wireless communications,"
Progress in Electromagnetics Research, vol. 83, pp. 133146, 2008.

[9]. A. K. Panda and Asit K. Panda, "A novel design of multiband square patch antenna embedded with gasket fractal slot for WLAN \& Wi-Max communication," Int. J. Advances in Engg. \& Tech. (IJAET), vol. 3, no. 1, pp. 111-116, 2012.

[10].W. C. Liu, "Optimal design of dual band CPW-fed Gshaped monopole antenna for WLAN application," Progress in Electromagnetics Research, vol. 74, pp. 2138, 2007.

[11].V. G. Kasabegoudar, "Dual frequency ring antennas with coplanar capacitive feed," Progress in Electromagnetics Research C, vol. 23, pp. 27-39, 2011.

[12].V. G. Kasabegoudar, "Low profile suspended microstrip antennas for wideband applications," Journal of Electromagnetic Waves and Applications, vol. 25, pp. 1795-1806, 2011.

[13].H. Zhang, H. Y. Xu, B. Tian, and X. F. Zeng, “CPW-fed fractal slot antenna for UWB application," Int. J. Antennas and Propagat., pp. 1-4, vol. 2012 (Article ID 129852).

[14].M. A. Maindarkar and V. G. Kasabegoudar, "CPW fed slot coupled wideband and multiband antennas for wireless applications," Int. J. Advances in Engg. \& Tech. (IJAET), vol. 5, issue 1, pp. 456-461, 2012.

[15].M. Darvish, H. R. Hassani, and Rahamati B, "Compact CPW fed ultra wideband printed monopole antenna with multi notch bands," Iranian Conference on Electrical Engg. (ICEE), pp. 1114-1119, 2012.

[16].Ansoft's HFSS Software v.11, Ansys Corporation, USA. 